\title{
Study on the Current Situation of Chinese Scattered Chicken
}

\author{
Yuqi Cao ${ }^{a}$, Wei $\mathrm{Li}^{\mathrm{b}}$, Jiahe $\mathrm{Cui}^{\mathrm{c}}$, and Dongming $\mathrm{Li}^{\mathrm{d}^{*}}$
}

College of Mechanical and Electrical Engineering, Hebei Agricultural University, Baoding, China

a2350353391@qq.com, b869306513@qq.com, '1301683942@qq.com, dLdmmail@163.com

Keywords: Scattered chicken; Intelligent chicken house; Chicken's market demand

\begin{abstract}
With the fast development of the society and people's rising awareness on healthy diet, scattered chickens have already become a consuming hot spot on the market. This paper firstly showed a comparison between traditional way and scattered way on the chicken raised pattern. And then some technology applications were introduced in raising scattered chicken.
\end{abstract}

\section{Introduction}

According to the USDA's statistic published in April 2018, broiler meat ranks second in the world meat consumption list right after pork, and beef ranks the third. In China, broiler meat's consumption reaches 13267k metric tons in 2015[1]. Affected by avian influenza, Chinese people pay a lot of attention on the food quality and are more careful when choosing the chicken product. Scattered chicken refers to a new way of keeping chicken in which chicken keepers use forest lands, bushes, grasslands or orchards etc to raise chicken. In this way, all the chicks are able to freely forage insects or weeds, drink natural water and have enough playground. This kind of chicken is extremely popular in Chinese market because of its higher protein, lower fat and better texture. Compared to the traditional way, the advantages of the scattered chicken raised model are obvious. In this paper, this new chicken raised model was studied to find out the long term motivation, the current situation and some technologies used in scattered chicken raise.

\section{Scattered Chickens}

This new raising model made the best of the land resources including insects, weeds and forage as chickens' food, the primary which was insects and weeds coming from the ground. The forage which can supply the inadequate nutrition was supplemented by the chicken keepers. There was enough space,fresh air, great view etc provided for chickens to do daily exercise under the forest land, bushes or orchards which could lower fat content and build chickens' body to resist diseases. The chicken dung was also the perfect fertilizer helping increasing soil mineral content. The circulation between chicken and the environment is shown in Figure1.

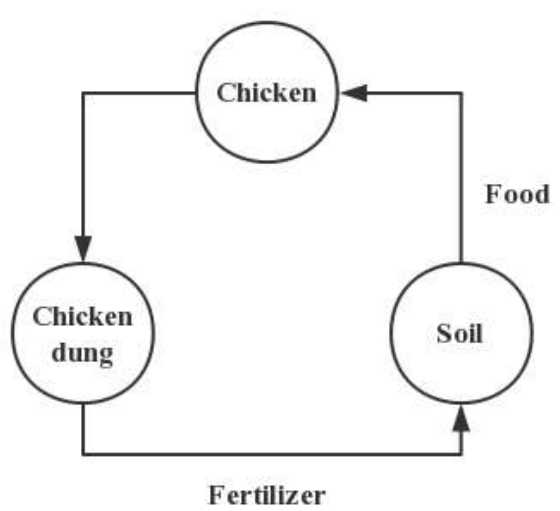

Figure 1. Circulation 
Comparison of meat quality. Scattered chickens have been welcome because of its high protein and low fat content and the protein content has become an important feature of distinguishing between scattered chicken and cage broiler. Suxia Xing and others made a nutrient component prediction based on the near-infrared reflectance spectroscopy (NIR) [2]. The physical and chemical experimental results are as respected. There were huge differences in protein and fat content among different chicken samples: richer and more diverse food resource, longer growth cycle and sufficient amount of exercise have made the scattered chicken contain higher protein, lower fat and more muscle fiber. Compared with the broilers kept in cage, minimal activity space, lack of exercise and exposure to sunlight, short growth cycle led to short muscle fibers, hypertrophy, low protein and high fat content. The statistics are shown in table 1.

Table 1 Comparison of protein and fat content

\begin{tabular}{ccc}
\hline Items & Protein content $(\%)$ & Fat content $(\%)$ \\
\hline Caged broiler & 23.225 & 3.517 \\
Scattered chicken & 30.558 & 1.328 \\
\hline
\end{tabular}

Comparison of egg quality. Raising environment would affect hens' laying ability. Research from Haiming Yang showed that scatter-fed chickens had poorer production performance and its reproductive system's development was affected [3]. While Lei Tian etc found out that scattered land had abundant forage resources and gravel resources which would be a positive factor on darkening yolk' color, strengthening eggshell's strength and increasing protein height [4].Statistics are shown in table 2.

Table 2 Comparison on egg quality

\begin{tabular}{cccc}
\hline Items & Albumen height $(\mathrm{mm})$ & Yolk color & Shell thickness $(\mathrm{mm})$ \\
\hline Caged chicken & $6.25 \pm 0.83^{\mathrm{B}}$ & $8.23 \pm 0.75$ & $0.31 \pm 0.03^{\mathrm{B}}$ \\
Scattered chicken & $7.31 \pm 1.17^{\mathrm{A}}$ & $8.68 \pm 0.70$ & $0.36 \pm 0.02^{\mathrm{A}}$ \\
\hline
\end{tabular}

Effects to scattered land. Xiangyan Zeng's research showed that fed chickens under forest would affect the scattered land on both soil physical properties and soil nutrient content [5]. Dong Lin's research showed that the improvement of soil by keeping chicken under the forest was related to chicken density and frequency of chicken activity [6]. Weijing Kang also analyzed the economic benefits of fed chicken in canopy poplar woodland, the result showed that the return on investment reached $25.8 \%$ [7]. Fed chicken under forest not only improved soil properties but also improved the fertility of soil, which was beneficial to the growth of forest, specific indicators trend compared to the contrast land are shown in table 3.

Table 3 Specific indicators

\begin{tabular}{cc}
\hline Items & Scattered land \\
\hline soil bulk density & decreased \\
pH value & decreased \\
total porosity & increased \\
the ratio of capillary porosity & increased \\
the ratio of non-capillary porosity & increased \\
nutrient contents & increased \\
microorganism number & increased \\
available phosphorus content & increased \\
Available potassium content & increased \\
Available nitrogen content & increased \\
available copper content & increased \\
\hline
\end{tabular}




\section{Current situation of scattered chicken}

Traditional ways of raising chickens. The chickens raised form has been changing with the development of society and productivity. Earlier, the basic form was peasant households raised chickens on a small scale, which may cause a lot of risks: the lack of disinfection and isolation measures, nonstandard use of vaccines and the lack of proper handling for dead chicken etc. In the 1980 s, under the government's support of policy and fund, large and medium-sized mechanized farms began to be established[8]. In the new period, China's chicken raised industry has been developing in a bigger scale, more standard and more ecological way[9].

Support from the government. Out of the consideration of environment and sustainable development, the country have published a series of policies on subsidy to improve the enthusiasm of farmers. Local governments also published policies to support the development of the ecological chickens. The Hebei province stepped up efforts to adjust agricultural and rural economic structure. In the 12th Five-Year Plan of Agricultural Development in Hebei province (2010 -2015), it was proposed to develop green and pollution-free firewood chicken breeding in mountain areas[13]. The Urumqi municipal government has continuously invested 500,000 RMB as support fund, and continued to support the cultivation of 27000 native chickens. TheUrumqi government has focused on the development of a certain number of breeding, epidemic prevention experience demonstration households, to encourage villagers to vigorously develop the ecological breeding of native chickens[12] .

Scattered way of raising chickens. There were 3 types of ecological chickens raised models: forest-grass-chicken model, chicken-vegetable model and orchard-bamboo garden-tea garden model[10]. The forest-grass-chicken model meant chickens were raised on open forest land, economic forest land or bushes, where high quality forage was served as one of chicken's main food resources. The chicken-vegetable model meant chickens were raised in vegetable green house. On the one hand, $\mathrm{CO} 2$ and dung the chicken released would be beneficial to the growth of vegetable, on the other hand the oxygen vegetables produced will be a supply for chickens. The orchard-bamboo garden-tea garden was that chickens were raised in gardens and the tree shade, and dung and the insects formed a ecological chain.

Many provinces in China have developed ecological chicken raised industry. In HuBei province, the excellent geographical and climatic conditions set a good foundation for the development of ecological chicken raised industry. HuBei province has already established 3 ecological chicken industry belts. These 3 industry belts have run several years and have already become powerful tools helping thousands of families to raise ecological chickens. While there were still some questions to solve. According to Ailuan Pan's paper, firstly, breeding system was not perfect lacking systematic breeding research and standardized production; secondly, local chicken genetic resources' development were lagging behind; thirdly, production methods were backward, many farmers lack of scientific technology and equipment [11].

Ecological resource conditions were superior for feeding native chicken in the suburb combination area of Shuimogou district, Urumqicity, where the air was fresh, the water was abundant and clean, and farmers and herdsmen livedin scattered, vast shrubs and grasslands. So a lot of farmers have already raised chicken in a scale and have primarily formed a set of methods. They built the chicken house among the mountains facing south where the wind was leeward, water was clean and the ground was dry. Chicks were taken care of sorted by maturity, and different sort of chicks' raising temperature, composition of its forage and ventilation differed. 5 to 8 weeks later, chicks would be fed in a scattered way, meanwhile its forage changed by time. This new raising model has already brought a lot of commercial chances but there were still some problems to solve such as nonstandard epidemic prevention[12].

Hebei province has always been chicken's main producing area. Since late 1900s, many places have started trying to raise laying hens in mountain farms and woodland. Zanhuang county, She county, Jingjing county and Baoding city, etc have created bands of ecological chicken products. And the chicken industry in Hebei has been developing in a more standard and more professional way[13]. 


\section{Applications of technology}

With the progress of science and technology, the productivity has been developing faster than before. Nowadays, more and more advanced techniques were involved in scattered chicken industry, which would save a lot of manpower and material resources.

In product collecting. It was quite manpower-costing to collect eggs by hands, especially in the forest where chicken houses were so far separated. The eggs that laid in the chicken house could be collected by automatic egg collectors which have already widely used in big chicken farms. For those eggs laid outdoors, an egg-collecting-car could be a good choice, which had the sensor part to identify eggs and collect part.

In chicken's health care. According to Zhaoyang Wang [14], analysis of health degree included the chicken's tiny movement, larger macro movements of chickens and the diet movements. Farmers could have general idea of each chicken's health condition through analyzing the motion change in a unit time and easy to find out the sick or the died chicken in time. When it's time for chicken to forage outside, expulsion devices could force the lazy one chosen by the analyze system to go outside .

In environment monitoring. There were a lot of factors that could affect chicken's living environment: temperature, humidity, $\mathrm{NH}_{3}, \mathrm{H}_{2} \mathrm{~S}, \mathrm{CO}_{2}$, etc [15]. Jinsheng Wang proposed a chicken house environment control system consisted of all kinds of sensors, ventilation system, heating system and alarming system [16]. When the temperature or the harmful gas concentration was over proof, the heating system or the ventilation system would automatically open.

In dealing with chicken manure. Long term fowl dung accumulation would pollute the environment, but it was good fertilizer to the soil. An automatic collecting-car could be used to collect fowl dung, transport to the outdoor and spread to the ground.

\section{Acknowledgments}

This work was supported by the Department of Science \& Technology of Hebei Province (16236605D-2), the Training Program of Students Innovation and Entrepreneurship in Hebei Agricultural University (201810086014), Key Laboratory of Broiler and Chicken Breeding Facilities, Ministry of Agriculture.

\section{References}

[1] Information on https://www.usda.gov

[2] S.X. Xing, P.Y. Guo and L.Z. Xiang, et al: Journal of Quality Inspection of Food Safety, Vol. 6 No.8, p.2994. (In Chinese)

[3] H.M. Yang, Y.J. Cao and X.C. Zhu, et al: Journal of Animal Nutrition, Vol. 25 No.8, p.1860. (In Chinese)

[4] L. Tian, T.S. Xu and X.Q. Lei, et al: Journal of Livestock Ecology, Vol. 33 No.3, p.89. (In Chinese)

[5] X.Y. Zeng, J.M. Liao and F.Y. Wei, et al: Guangxi Forestry Science, Vol. 43 No.3, p.292. (In Chinese)

[6] D. Lin, L.M. Zhong and P. Zheng, et al: Hubei Agricultural Science, Vol. 52 No.18, p.4346. (In Chinese)

[7] W.J. Kang, X.C. Xiao and J. Song, et al: Hunan Forestry Science and Technology, Vol. 40 No.4, p.22. (In Chinese)

[8] W. Han: Poultry Science, 2005 No.3, p.6. (In Chinese)

[9] N. Zhu, F. Qin: Chinese Poultry, Vol. 38 No.20, p.1. (In Chinese)

[10] L.L. Zhu, X. Han, Y.H. Tao: Seminar on High-Efficiency Ecology (Organic) Characteristic Agriculture in Guizhou Province (Guiyang, Guizhou, China, December 1, 2011). 2011, p.4. (In Chinese)

[11] A.L. Pan, C.G. Li and J. Shen, et al: Hubei Agricultural Science, Vol. 52 No.23, p.5800. (In 


\section{Chinese)}

[12] A.H. Sun, L.T. Feng and G.Q. Li, et al: 2015 China Grassland Forum (Xilinhaote, Inner Mongolia, China, August 26, 2015). 2015, p.3. (In Chinese)

[13] C.S. Zheng: North Livestock, 2014 No.6, p.15. (In Chinese)

[14]Z.Y. Wang: Study on Key Technologies of Intelligent Ecological Chicken raised System(master degree, Central North University, China 2016), p.38. (In Chinese)

[15] X. Zhong, G. Li, S.L. Xu, et al: Animal Husbandry and Veterinary Medicine, Vol. 45 No.3, p.101. (In Chinese)

[16] J.S. Wang, X.P. Wu, Y.B. Jiang: Chinese Poultry, Vol. 35 No.10, p.2. (In Chinese) 